\title{
Issues in Multi-Method Research: Constructing Self-Care
}

\section{Danny Meetoo and Bogusia Temple}

Danny Meetoo, BSc(Hons), MSc, PhD, Lecturer, University of Salford, England

Bogusia Temple, BA, MPhil, PhD, Senior Research Fellow, University of Salford, England

\begin{abstract}
In this article, the authors examine claims that using more than one method in research automatically enhances validity. They argue that if the findings from different methods are the same this does not automatically prove the study is valid. It may show that the researchers looked only for evidence that supported the findings from one method.

Complementarity of methods does not mean that different methods have to produce the same findings. That different methods work together as equal partners has to be demonstrated rather than assumed. A study of self-care in relation to people with diabetes is used to draw out some of the issues in the operationalisation of multiple method validation.
\end{abstract}

Key words: triangulation; multiple methods; complementary methods; epistemology; research methods; diabetes.

\section{Citation Information:}

Meetoo, D., \& Temple, B. (2003). Issues in multi-method research: Constructing self-care. International Journal of Qualitative Methods, 2 (3). Article 1. Retrieved [INSERT DATE] from http://www.ualberta.ca/ iiqm/backissues/2_3final/pdf/meetootemple.pdf 


\section{Introduction}

Janice Morse and her colleagues argue persuasively that qualitative researchers should not dismiss concerns about reliability and validity, as these are not the domain of quantitative researchers alone. As they point out (Morse, Barrett, Mayan, Olson, \& Spiers, 2002), qualitative researchers in Great Britain and Europe have continued to use these terms. Morse et al. argue that though using criteria such as trustworthiness "may be useful in attempting to evaluate rigor, they do not in themselves ensure rigor" (p. 2). Researchers in Great Britain have recently redefined and reclaimed the concepts of reliability and validity and begun to debate what they mean to a qualitative researcher. There is now a debate on the definitions of these concepts in terms that have not been set by quantitative researchers (e.g., Temple, 1998; Popay, Rogers, \& Williams, 1998). In this article, we focus on validity and on one strategy that has been put forward as a way of ensuring validity: the use of multiple methods. We examine the increasing trend towards combining different methods in health research in order to validate research. We argue that, though findings from different methods may reinforce each other, researchers seldom spell out any tensions between findings and almost never spell out the contradictions. Different methods have different strengths and they may in fact be looking at different aspects of reality. It is therefore odd that the picture across studies using different methods is so rosy. We examine a study on self-care in relation to diet for people with diabetes to operationalize the use of multiple methods in a way that foregrounds a multi-dimensional view of reality. 


\section{Epistemology and combining methods}

In this article, the term epistemology is taken to mean the theory of knowledge production. That is, it is taken to cover such questions as 'what counts as valid knowledge?' and 'who is allowed to be seen as knowledgeable about an issue?' Discussions of epistemology would therefore cover philosophical debates about reality and how we can know our social world. Methodology is defined here as the approach we use to research - for example, an ethnomethodological or narrative approach - and method is the technique for carrying out the research (for example, a survey or in-depth interview). We realize, of course, that these issues are not completely separable in this way but we use these definitions to allow a discussion to take place. We introduce the question of the researcher's epistemology to show that there may be different views on how multiple methods work together according to the researcher's view of what counts as valid knowledge.

Hammersley (1992) provides one qualitative perspective on validity when he states that "An account is valid or true if it represents accurately those features of the phenomena that it is intended to describe, explain or theorize" (p.69). This statement raises many questions about the nature of qualitative research and this is discussed below. It does, however, point to the way in which qualitative researchers concerned with validity aim to examine whether they have achieved what they set to do. One way researchers have tried to establish their research as 'valid' is by combining different methods to compare the results, a strategy often called 'triangulation'. Fitzpatrick and Boulton (1994) provide a usefully straightforward definition when they describe it as the use of as wide a range of sources as possible to support statements (also referred to as multi-method, complementary methods). There are many different kinds of triangulation, such as triangulating between different researchers, re-checking accounts with 
respondents, and theoretical triangulation (see here Mason, 1996), but we focus here on the most commonly used which is triangulation of method. However, many of the points made apply equally to the other kinds of triangulation.

Researchers often argue that they use multiple methods to enhance validity. For example, Kellaher, Peace, and Willcocks (1990) state that qualitative and quantitative data can cross validate each other around "a common reference point" (p. 121). Fitzpatrick and Boulton (1994) also argue that triangulation is about looking for patterns of convergence that 'corroborate' an overall interpretation, and state that it is important when possible or appropriate to look for quantitative evidence to 'check' or 'test' qualitative statements. However, there have been concerns expressed about the conceptualisation and use of triangulation for the validation of qualitative research (e.g., Bryman, 1988; Devine \& Heath, 1999; Mason, 1996; Mitchell \& West, 1996; Silverman, 1993; Temple, 1997). These writers focus on the assumptions of researchers who advocate triangulation or complementarity of methods in an unproblematic way to validate around a common reference point. Here we examine one of these assumptions: that different methods pick up the same kinds of information and can be pieced together to form one unproblematic view of social reality. We point to the importance of specifying the epistemological premises behind a researcher's use of multiple methods to enhance validity.

Many researchers have reviewed the complex debate on the basis of knowledge claims, or epistemology. We engage in this debate only far enough to establish the links between epistemology and validity. (See Hammersley [1989, 1995], Silverman [1993], and Stanley and Wise [1993] for a fuller description of some of the debates.) The pursuit of objectivity in research has also been variously named as, for example, positivism, the scientific model, 
foundationalism and the medical model of research. Here, researchers' concerns focus on achieving objectivity and unbiased examination of social reality. However, many researchers take issue with the position that social location does not affect the research if it has been carried out 'correctly'. Working with an alternative paradigm, many social scientists argue that there is no one 'true' account of social reality but that research participants construct accounts of social reality. (See, for example, the influential work of Berger and Luckmann [1991] and Hertz [1997] on this topic.) Everyone, including the researcher, sees social reality from their own position within the world. Indeed, one of the strengths often put forward for using qualitative methods is that they allow the researcher to discuss the views of research participants and to reflect on the influence of their own social location on their perspective (Young, 1997; Hertz, 1997). They, therefore, do not see research as discovering one 'true' account or of all data referring to one common reference point. Rather, they see research as a social activity during which researchers and research participants produced an account that is context specific. This view of reality has been variously named as social construction, phenomenology, and interpretative, amongst other labels. What they have in common is the view that social reality cannot be unproblematically described from one correct perspective.

Quantitative and qualitative methods have traditionally been associated with different epistemologies: qualitative methods with the approach described above as interpretative and quantitative methods with positivist approaches. Social scientists are increasingly recognising, however, that there are problems in attempting to tie a worldview or epistemology to a particular quantitative or qualitative method, especially if researchers are attempting to use both kinds of methods. Qualitative researchers can argue for a positivist approach, that is, that they are 
objectively analysing the real world. Alternatively, quantitative researchers may adopt a more interpretative approach. For example, Mitchell and West (1996), in a study of peer group pressure to smoke tobacco, view all the methods they used (survey, focus groups and role play) as accounts of actively constructed interactions between researchers and research participants.

Which paradigm of research is adopted is important to the way the use of multiple methods are used as a yardstick for validity. If one holds a positivist view of research, then epistemologically there is no problem with adding findings from qualitative and quantitative methods in a complementary way to achieve one view of the phenomena being studied. All the methods, correctly and objectively undertaken, can be added together to produce a 'true' account of reality. If there is a divergence of findings, these discrepancies have to be ironed out and only one set of findings can be 'true'.

However, if one subscribes to the interpretative view of social reality, then the context and conditions under which data have been produced are crucial and adding together data collected from different methods is problematic. The research process is as important as the research findings. This does not mean that comparing results from different methods is of no value. We are arguing the opposite, that it is of value because social reality is multi-faceted and perspective is all-important. Using different methods may allow a researcher to investigate the different ways that accounts are built up. Different methods may be used to verify each other, but they may also be complementary and contradictory. Complementarity does not imply that findings have to be identical (see also Morse, 2001). 
Adopting an interpretative epistemology makes it problematic to add findings together without considering the possibilities for contradiction and difference that arise from the centrality of context and the process of data production. Combining methods or triangulation cannot be about validating one set of findings by findings generated via another method. Bryman's (1988) view of triangulation is that it is not a way of enhancing validity per se but "it is in the spirit of the idea of triangulation that inconsistent ideas may emerge" (p.134). He goes on to argue that it is not in its spirit that the researcher "should simply opt for one set of findings rather than another" (p. 134). In a similar vein, Devine and Heath (1999) state that "triangulation can be used effectively to explore the dynamics of complex social phenomena, highlighting the multi-layered and often contradictory nature of social life" (p. 49). Mason (1996) sums up the argument for this kind of triangulation when she argues:

At its best, I think the concept of triangulation - conceived as multiple methods encourages the researcher to approach their research questions from different angles, and to explore their intellectual puzzles in a rounded and multi-faceted way. This does enhance validity, in the sense that it suggests that social phenomena are a little more than one dimensional, and that your study has accordingly managed to grasp more than one of those dimensions. However, the use of the term 'triangulation' for this best case scenario is possibly misleading since it is commonly understood to be a technique for checking out one method against another. The general message, then, is that you should not expect the use of multiple methods or triangulation to provide an easy or well-trodden route to the demonstration of validity of method (p. 149).

Using this approach, contradiction and tension between findings generated by different methods are to be valued and explored and not used to judge whether one set of findings produced under specific conditions are validated by findings produced under different conditions . Cockburn (1991) has described these contradictions as "the motor of change" (p. 572). 
Different methods use different processes to construct findings and these different processes are valuable in contextualising data generated in different ways. For example, one of the benefits of in-depth interviews are that they allow for dialogue and debate around what a concept means, whereas a questionnaire is often a de-contextualized choice of tick boxes. In social life we are often presented with both ways of choosing. Sometimes we have to choose between two fixed alternatives without being able to give the 'ifs' and 'buts'. At other times we can say that our views are dependent on a number of issues. Research can also be viewed as a social exchange between researchers and research participants and different methods are used for specific purposes. Some of these allow for discussion, others do not. Whatever method researchers use, who they are within the context of the research is crucial to kind of data collected (see also here Wilkinson, 1998, for a useful debate of the differences between focus groups and interviews).

The kind of triangulation envisaged above positions it within a much broader definition of validity than put forward by researchers using it as a means of judgement about the 'truth' claims of their research. We support Mason's (1996) suggestion for viewing validation in terms of data generation and interpretation. She argues that the former can be seen in both broad and detailed ways. In broad terms, the qualitative researcher would ask how well matched the logic of the method was to the kinds of research questions asked; that is, what is the methodological strategy and is it appropriate? At a more detailed level, validation involves showing how particular methods, aspects of methods, or data sources are appropriate ways to look at research questions. Validity of interpretation involves investigating the basis of data analysis and the interpretation upon which it is based. Mason suggests that the way to do this is for the researcher to spell out the approach so that the reader can engage with the interpretation. In this view, it is important to 
look at how research findings are produced and at how research processes affect what can be produced, that is, at the epistemological and methodological claims that are being made. This view of validity brings epistemological claims out into the open and has been put forward by other qualitative researchers in Great Britain (see, for example, Popay et al., 1998; Temple, 1998). Researchers should spell out their research process and their epistemological and social position within their research to enable the reader to actively engage with the arguments being put forward.

We now examine how the approach discussed above was operationalized in a study of self-care among persons with diabetes. We briefly examine our construction of the concept of self-care, the study itself and the results. We then discuss our perspective on combining methods in the study.

\section{Self-care}

Chronic conditions are a major health problem in today's society and their management depends largely on the efficacy of self-care (MacClean, 1989), a concept which is equally important in disease prevention and health promotion programmes. Diabetes mellitus (DM) is a chronic condition with a well-understood patho-physiology (Glasgow, 1995). The consequences of poor glycaemic control can be potentially life threatening, both in the short-term (e.g. acute hypoglycaemic reactions, recurrent keto-acidosis) and long term (micro-vascular and macrovascular complications associated with chronic hyperglycaemia, such as blindness, peripheral neuropathy, and heart disease (Vallis, 1998)). The long-term management of diabetes rests primarily on the individual. Therefore, the role of self-care is well recognized as a major focus of 
clinical intervention and education. However, for many individuals, following an agreed regimen of self-care is extremely difficult.

Although there has been some research into self-care behaviour, it is still an underexplored area of health research (Dean, 1986; Haugh, Wynkle, \& Namazi, 1989; Rakowski, Hickey, \& Dengiz, 1987). Definitions of self-care are fraught with problems. They are imprecise and variable and generally appear to be discipline specific, suggesting that the analytical focus differs from study to study. For example, Haugh, Akiyama, Tryban, Sonoda, \& Wynkle (1991) define self-care in terms of response behaviour to a perceived symptom without the involvement of the doctor. These responses include deciding to do nothing, resting, taking over the counter medicine and resorting to various forms of self-treatment and care provided by family members without concurrent medical advice.

A contrasting, often implicit, definition is that self-care is non-professional care (Bentzen, Christiansen \& Pedersen, 1989). In this context self-care refers to care activities carried out by the individual with certain aspects omitted. On the other hand, Dean's (1989) definition represents self-care as "the range of behaviour undertaken by the individuals to promote or restore health" (p.117). This broad definition encompasses self-care actions in either the presence or absence of medical supervision and further recognizes its significance in both health and illness.

Dean (1989) assumes that the daily management of chronic conditions, such as diabetes, is a routine regularly undertaken by the patient and supported by his/her family as well as the health 
care team (see also Etzwiler, 1994; Funnell et al., 1991). However, this is not always the case. It is important that self-care actions are understood in terms of the meanings attached to them and the context in which they take place, the norms they are subject to and the resources available to the individuals (Kickbusch, 1989). In this article we define self-care using Dean's (1989) broad definition but do not assume that chronic conditions are managed in any particular way or that they have the same significance or meaning to everyone.

The notion of self-care with regard to a recommended diet is considered important in order to avoid life-threatening complications associated with diabetes. It would therefore be reasonable to assume that motivation to follow a healthy diet would be high. However, studies relating to whether people with diabetes follow dietary advice suggest that the majority do not (see for example Ary, Toobert, Wilson, \& Glasgow, 1986; Lockwood, Frey, Gladish, \& Hiss, 1986; Vallis ,1998). Many of these studies seek causal linkages to explain 'non-compliance'.

Consequently, they ignore the constellation of meanings associated with living with diabetes and the relationship of these meanings to social and cultural context (MacClean, 1989). It is this context and depth that this research project aimed to examine by including qualitative methods.

\section{The study}

The purpose of the study was to explore the notion of self-care in the context of diet for a group diabetic patients. A purposive sample of forty-nine participants were recruited from the local diabetic clinic. One of the factors considered to be important in sampling was the influence of ethnicity on adherence to diet since ethnicity has been shown to be related to diabetes. Gender was also considered a factor in relation to diabetes. The sample was made up of 18 men and 31 
women. Criteria for inclusion were: adult patients with a diagnosis of Insulin Dependent Diabetes Mellitus (IDDM) or Non Insulin Dependent Diabetes Mellitus (NIDDM), diagnosed for over a year, without known mental health issues. Their ages ranged from 20 to 80 years old.

Semi-structured interviews comprised of fifteen questions were conducted by one of the authors (Meetoo), a nurse with a specific interest in diabetes. The interviews took place in the homes of the participants. The time taken to complete each interview ranged from forty five to ninety minutes. The interview questions included: what it meant to be healthy; why some groups of people are statistically more likely to be affected by diabetes; how they would describe the experience of being a diabetic; what they personally thought had caused their diabetes; and examples of instances when they found their treatment hard or had not followed recommended treatment. Each question included prompts.

The interviews were followed by a thirty-five item tick-box questionnaire about diet. The interviewer then left a diary to be completed over the next 7 days. To illustrate our arguments, we compare how people presented their self-care dietary behaviour in the interviews and the diaries. (Copies of the interview schedule, questionnaire and diary can be obtained from the authors.) The diary stated that the interviewer was interested in how they looked after their diabetes on a day to day basis for a period of seven days. Examples were given of the kinds of everyday self-care issues that the study was concerned with, such as how diabetes effected their social life, whether they had to carry insulin when they went out, if they had skin care issues, and if they exercised. 
Approval was obtained from the Local Research Ethics Committee. The study was undertaken with informed written consent in accordance with the Helsinki Declaration.

\section{Results}

A decision to place individuals on a continuum was based on a detailed analysis of their comments in the interviews about their eating patterns, the types of food they consumed, their perceptions of their conformity to the recommended dietary regimen and their general philosophy of diabetes management. Dietary prescriptions vary. Many people are given a strict diet to follow that they modify over time. Participants' responses to a diet suitable for someone with diabetes were on a continuum ranging from strict adherence, moderately flexible adherence, and very flexible adherence to dietary intake.

The first group of people $(n=16)$ believed that following dietary advice was essential for good health. This was a form of insurance against complications. Analysis also indicated that these participants preferred an orderly and methodical life. Several of them stated that they did not have a 'sweet tooth' and therefore did not find the dietary restrictions onerous. For example, one man expressed reasons as to why he followed the strict dietary advice he had been given:

I have always complied with my treatment. I try my very best to keep my sugar level under control because if I don't my sugar goes high and I start getting pains etc. ... even at parties and weddings I avoid all foods which are a risk to my health. If they are serving fizzy drinks, I will always ask for water.

When asked about responsibilities related to controlling diabetes, one woman explained: 
Well, you've got to, not to miss your injections, of course. You've got to eat at regular intervals, erm, and generally look after yourself and watch out for warning signs of something going wrong. [prompt: was there a time when you didn't compy with any aspect of your self-care] No because I make it a thing to comply with that treatment. The only time even when I've been ill, you know, when I've been in bed ill, I've still tested and had my injections the same and I've rung the doctor to make sure whether I had to reduce the insulin or what to do, you know, but erm, it's a way of life for me I'm afraid. I look at it that way. I've got it and I've got to keep going, there's only me will suffer.

A second group on the continuum $(n=17)$ included those who took a moderately flexible approach to diet. To live a 'balanced life' was the guiding principle. They spoke of allowing for indulgences (labelled as cheating) when they gave themselves permission to eat without spoiling such pleasure with guilt. They also described a more liberal pattern of eating and adjusted their insulin dosage according to their consumption of restricted foods. Although they did not wish to unduly compromise their health, they refused to allow the diet to dominate them. One man commented :

What I believe, everybody got his opinions and the people who follow the instructions, they will be getting better in their diabetes. But people like me who have been to clinics for years and years, I believe they [doctors] are doing same routines, taking blood and the urine but there is no cure for diabetes.... Yes I mean normally in weddings, rice, but if you too much rice you have to be careful. .... Well sometimes I care about it but sometimes I have to eat it.... That's right, yes. Like I eat so much food at weddings or parties, that's what I do (adjusts dose of insulin).

The third category of people $(\mathrm{N}=16)$ on the continuum reported taking a very flexible approach to their diet. They ate restricted food more frequently than the moderately flexible group. Their behaviour was not overly risky because they monitored their blood glucose and adjusted their insulin accordingly. They spoke of desire for foods in certain instances and of a lack of understanding and preparation by the diabetic health care team. A more flexible approach to dietary non-compliance was noted, for example, by two women who remarked: 
I never comply with my treatment at weddings or parties. If other diabetics eats sweets and desserts at parties, why should I not enjoy myself? Parties are about food. After eating the wrong foods, I do go ill but I also recover in a couple of days.

When I attend parties etc I always eat and drink what's there. I can't ask for diet drinks. I like to enjoy myself .

A third woman contended:

What annoys me they (professionals) expect everybody to be little tin soldiers, we all follow the same, whereas we don't, I mean I've a friend who can sit and eat cream cakes yet she is diabetic. I couldn't sit and even look at a cream cake, it'd send it straight up. To me they expect so much of you yet they never ever, nobody's ever told me the actual problems of diabetes. ....... you just get on with it and that's it, that's the attitude I got first. Finding out about it I think, because people don't understand it. ........ the first consultant I saw I could have thumped him literally. He sat there and my husband was there and he was saying 'you must sit and eat this, you must do this and all your weight's this' and I said no it's not because I don't eat a quarter of what my husband eats. ........ so I've said no, sod off, I'm doing it my way and it's working now. I've lost a stone in the last month.

There are many examples of people confirming statements from the interviews in their diaries.

Here we focus on three examples where the entries in the diary differ from views expressed in the interviews. The first two people were classified as belonging to the first group of responses, that is, they believed following dietary advice was essential for their good health. Mr. Alexander was 58 years old and during the interview he stated:

You have to live a well-ordered life. You've to accept that there's a much stricter regime to life than there ever was before. Gone are the days when you could go out after breakfast and not bother having anything to eat until you came home at tea time. I've responsibilities to make sure that I eat the right foods at the right time in order that I can control the diabetes. I'm controlling my diet, erm, my food is all grilled and not fried.

This is in contrast to the dietary routine he described in the diary. He noted that he had eaten a sausage muffin, a packet of crisps, various types of red meat, meat and potato and pork pies, 
chicken curry and rice. His blood glucose had been abnormal during this 7-day period. In a similar way, Mrs. Smith, aged 32, said in the interview:

Well, I've got to be sensible about my diet, erm, you know, I've cut down on the fatty foods and the sweet sugary foods and plenty of protein and stuff. I've got to do that, erm, I've got to eat, erm, eat more or less at the same time everyday and try and take my insulin at the same time everyday. I think it's all about routine.

This compares to the diary in which she wrote:

Had a full English breakfast: eggs, mushrooms, bacon, tomatoes, toast etc. (Another entry read) Went to restaurant. For starter had stuffed mushrooms, main course, chicken, chips, vegs, dessert chocolate cake and cream and about 5 lagers... Came back and had a couple more lagers. Watched a video and went to bed. Soon as my head hit the pillow I fell asleep.

The third person, Mr. Peters, differed from the first two discussed so far in that he was classified as in group two, as he had a moderately flexible approach to diet. In his interview, he said:

Erm...food...I do lapse especially when I am out. For example we went away last weekend, we went to Blackpool for a weekend, we just had a good time because it was Jackie's husband's birthday, $40^{\text {th }}$ birthday.... but funnily enough, having said that I broke what I would count quite a few rules by the fact that I had a few drinks and wine at the night, don't ask how much, and I had sweets, sweets with my meal. So you think now, were that wrong or were that right?

In the diary he wrote:

Its dinner (lunch) time and I have to eat healthy to keep blood glucose down. For dinner I cooked small slice of grilled ham without any fat on it, boiled potatoes, steamed cauliflower, new carrots and a mug of tea. I washed up and went in the garden for a walk and in the greenhouse to watch the plants.

The results from the interviews and diaries provided many points of overlap. However, comparing the main messages from the interviews and diaries there is evidence that using different methods produced some different data. The methods used, we believe, complement 
each other in that they form the basis for a discussion of the way people saw self-care and how this varied according to the context.

\section{Discussion}

The diabetes study described in this article attempted to operationalize the use of multiple methods in a way that foregrounds a multi-dimensional view of reality. From a positivist frame of reference, it is easy to move the two respondents who gave contradictory accounts of their behaviour to an alternative category of response. This would involve adjudicating between the account in the diary and that in the interview. The researcher would have to make a judgement that the respondent had either misled the researcher in the interview or that the diary period was unusual in some way. However, employing a wider view of validity and the purpose of using multiple methods, the two accounts were treated as different data produced under different circumstances and as equally valid.

Elliot (1997), in a review of the research literature on diaries, has argued that diaries are written with a particular reader, that is, the researcher, in mind rather than a general audience. It is interesting in the diabetes study, therefore, that even though Mr. Alexander and Mrs. Smith knew the study was about diet they felt able to articulate in writing that they were not keeping to their diets, whilst in the interviews they painted a different picture. The concept of self-care constructed in their interviews appeared to be one based on the medical model of strict adherence to a dietary regime. The interviewer, a nurse, was an important part of the picture here in that, it could be argued, it may have been difficult to express an alternative 'non-compliant' view of self-care in front of a medical audience. Writing in a diary may not, however, involve the same 
threat of possible confrontation over variation in adhering to a dietary regime. It is also important here that writing in a diary can be seen as a much more deliberate act in which there is time to decide what to put in writing. There is therefore less immediate comeback and more deliberation involved in filling in the diary. However, there may still be an issue about leaving a permanent written record that for some people is an issue. Mr. Peters provides an example of someone who felt able to articulate his variation from dietary recommendations at the interview but not on paper. Writing a diary or making comments during an interview are at the same time both private and public acts. People may be more comfortable in expressing particular views on one or other occasion. That is one of the advantages of using more than one method.

The above point about the importance of the circumstances in which people are prepared to make particular points mirrors everyday life. People make seemingly contradictory statements all the time. These are tied to the circumstances, including the audience, at the time. The model of selfcare presented in interviews and in diaries can therefore also vary according to circumstances. On some occasions people may feel it more appropriate to define self-care in terms of compliance to medical advice. In others, self-care may be seen as behaviour that does not involve professional advice.

Many of the qualitative researchers cited in this article (see, for example, Hertz, 1997, and Stanley \& Wise, 1993) point out that there are many possible perspectives on social reality. If this is the case, contradictory findings could be used to reflect on the reasons for these differences. Questions of power and control in health and social care in England are raised in issues such as the extent of involvement of service users in service development and research. 
These debates pose questions such as what is health and disease, who decides what are important research questions and whose 'truth' is the 'real truth'? Some of the issues around medical power may be played out around the temptation to define the validity of the account according to medical criteria. In the diabetes study the contradictions between findings were not ironed out. They were treated as valuable data in their own right and as indications of how people present accounts of self help in different circumstances.

\section{References}

Ary, D., Toobert, D., Wilson, W., \& Glasgow, R. (1986). Patients perspective on factors contributing to non-adherence to diabetes regimen. Diabetes Care, 9, 168-172.

Bentzen, N., Christiansen, T., \& Pederson, K. M. (1989). Self-care within a model for demand for medical care. Social Science And Medicine, 29 (2), 185-193.

Berger, P., \& Luckmann, T. (1991). The social construction of reality: A treatise in the sociology of knowledge. Hammondsworth, UK: Penguin. (Original work published 1966).

Bryman, A. (1988). Quantity and quality in social research. London: Unwin Hyman.

Cockburn, C. (1991). Brothers: Male dominance and technological change. London: Pluto.

Dean, K. (1989). Conceptual, theoretical and methodological issues in self-care research. Social Science and Medicine, 29, 117-123.

Dean, K. (1986). Self-care behaviour: Implications for aging. In K. Dean, T. Hickey, \& B. Holstein (Eds.), Self-care and health in old age (pp. 58-93). Dover, UK: Croom Helm.

Devine, F., \& Heath, S. (1999). Sociological research methods in context. Basingstoke, UK: Palgrave.

Elliott, H. (1997). The use of diaries in sociological research on health experience. Sociological Research Online, 2 (2), Retrieved April 14, 2003 from http://www.socresonline.org.uk/ socresonline/2/2/7.html

Etzwiler D. (1994). Diabetes translation: A blue print for the future. Diabetes Care, 17 (1), 1-4. 
Fitzpatrick, R. \& Boulton, M. (1994). Qualitative methods for assessing health care, Quality in Health Care, 3, 107-113.

Funnell, M., Anderson, R., Arnold, M., Barr, P., Donelly, M., Johnson, P., Taylor-Moon, D., \& White, N. (1991). Empowerment: An idea whose time has come in diabetes education. Diabetes Educator, 17, 37-41.

Glasgow, R. (1995). A practical model of diabetes management and education. Diabetes Care, $22,30-37$.

Hammersley, M. (1989). The dilemma of qualitative method. London: Routledge.

Hammersley, M. (1992). What's wrong with ethnography? London: Routledge.

Hammersley, M. (1995). The politics of social research. London: Sage.

Haugh, M., Wynkle, M., \& Namazi, K. (1989). Self-care among older adults. Social Science and Medicine, 29, 171-183.

Haugh, M., Akiyama, H., Tryban, G., Sonoda, K. \& Wynkle, M. (1991). Self-care: Japan and the US compared. Social Science and Medicine, 33, 1011-1022.

Hertz, R. (Ed.). (1997). Reflexivity and voice. London: Sage.

Kellaher, L., Peace, S., \& Willcocks, D. (1990) Triangulating data. In S. Peace (Ed.), Researching social gerontology: Concepts, methods, and issues (pp. 115-128). London: Sage.

Kickbusch I. (1989). Self-care in health promotion. Social Science and Medicine, 29, 125-130.

Lockwood, D., Frey, M., Gladish, N., \& Hiss, R. (1986). The biggest problems in diabetes. Diabetes Educator, 12, 30-33.

MacClean, H. (1989). Patterns of diet related self-care in diabetes. Social Science and Medicine. 32, 689-696.

Mason, J. (1996). Qualitative researching. London: Sage.

Mitchell, L., \& West, P. (1996). Peer pressure to smoke: The meaning depends on the method. Health Education Research, 11, 39-49.

Morse, J. (2001). Qualitative verification: Building evidence by extending basic findings. In J. Morse, J. Swanson, \& A. Kuzel (Eds.), The nature of qualitative evidence (pp. 203-220). London: Sage. 
Morse, J. M., Barrett, M., Mayan, M., Olson, K., \& Spiers, J. (2002). Verification strategies for establishing reliability and validity in qualitative research. International Journal of Qualitative Methods, 1 (2), Article 2. Retrieved March 17, 2003 from http://www.ualberta.ca/ iiqm/backissues/1_2Final/pdf/morseetal.pdf

Popay, J., Rogers, A., \& Williams, G. (1998). Rationale and standards for the systematic review of qualitative literature in health services research. Qualitative Health Research, 8, 341351.

Rakowski, W., Hickey, T., \& Dengiz, A. (1987). Consequence of health and treatment perceptions among older patients and providers of primary care. Journal of Aging Human Development, 25 (1), 63-87.

Silverman, D. (1993). Interpreting qualitative data: Methods for analysing talk, text and interaction. London: Sage.

Stanley, L., \& Wise, S. (1993). Breaking out again: Feminist ontology and epistemology. London: Routledge.

Temple, B. (1997). A marriage of convenience: Combining methods of research on advice giving for over-the-counter medication. Health Care Analysis, 5, 168-171.

Temple, B. (1998). A fair trial? Judging quality in qualitative research. International Journal of Social Research Methodology, 1 (3), 205-215.

Vallis, M. T. (1998). Understanding diabetes non-adherence: Psychosocial factors associated with poor self-care. Canadian Journal of Diabetes Care, 22(4), 13-21.

Wilkinson, S. (1998). Focus group methodology: A review. International Journal of Social Research Methodology, 1 (3), 181-203.

Young, I. (1997). Intersecting voices: Dilemmas of gender, political philosophy and policy. Princeton, NJ: Princeton University Press. 